\title{
A contribuição de Bilac para a crônica brasileira
}

Álvaro Santos Simões | UNESP/Assis

\begin{abstract}
Resumo: Com seu "Registro", coluna de crônicas diárias publicadas no vespertino carioca A Notícia de 1900 a 1908, Olavo Bilac (1865-1918) foi responsável por uma importante inovação no gênero. Até então, os cronistas desempenhavam em suas colunas hebdomadárias uma função de certo modo pré-determinada pelos jornais: a de comentar os principais acontecimentos da semana transcorrida; constrangidos por esse compromisso profissional, produziam textos compostos de fragmentos beterogêneos. No "Registro", o poeta parnasiano conquistou a liberdade de tratar de um único tema e de discorrer livremente sobre qualquer assunto a partir de um ponto de vista estritamente pessoal.

Palavras-chave: Literatura brasileira; Crônica; Olavo Bilac.
\end{abstract}

Gênero de origem francesa que se aclimatou muito bem ao Brasil, a crônica foi cultivada por alguns de nossos grandes escritores. Francisco Otaviano e José de Alencar são costumeiramente lembrados como fundadores da crônica no Brasil. Em Machado de Assis, reconhece-se o cronista excepcionalmente talentoso. ${ }^{1}$ Olavo Bilac, que merece um lugar de destaque entre os principais cronistas

1. v. COutinho, 1997 , v. 6, p. 117-43. 
brasileiros, deu ao gênero uma contribuição que deveria ser devidamente valorizada. Segundo Afrânio Coutinho, "a novidade que Bilac introduziu foi concentrar os seus comentários em determinado fato, acontecimento ou idéia, o que concorreu para dar a algumas de suas crônicas a feição de ensaios" .

No entanto, mais importante do que a concentração temática eventualmente obtida - mediante artifício retórico - nas crônicas que Bilac escreveu para a Cidade do Rio e para a Gazeta de Notícias foi o caráter pessoal que o poeta imprimiu à sua coluna "Registro", publicada no vespertino carioca A Notícia, onde o poeta gozava da liberdade de não apenas tratar de um único tema, mas também de discorrer livremente sobre qualquer assunto do seu ponto de vista estritamente pessoal. Para que se compreenda a inovação introduzida por Bilac, é necessário conhecer as condições a que um cronista costumeiramente se submetia em um diário. Considere-se, por exemplo, a colaboração do próprio poeta num dos principais jornais cariocas.

\section{A crônica dominical da Gazeta de Notícias}

A Gazeta de Notícias era um jornal popular para os padrões do final do século XIX; foi a pioneira da venda avulsa, iniciativa que a colocou ao alcance de todos os bolsos. Sua tiragem de 40.000 exemplares era bastante respeitável. Embora fosse moderada em suas posições, mais de uma vez desafiou os interesses do poder constituído. Nas "Balas de estalo" (primeira série, 18831886), por exemplo, coluna de crônicas impregnadas de ironia, o imperador Pedro II tornava-se alvo preferencial de críticas e zombarias. Atribuía-se ao seu diretor e principal editorialista, Ferreira de Araújo, o condão de orientar a opinião pública. Colaboraram nesse jornal influente escritores do porte de Machado de Assis, Eça de Queiroz, Ramalho Ortigão, Aluísio Azevedo, Raul Pompéia, Coelho Neto, Artur Azevedo e José Veríssimo, entre outros. Escrever para a Gazeta consagrava um escritor.

Durante muitos anos, a folha de Ferreira de Araújo possuiu apenas quatro páginas, mas cada página trazia oito colunas largas impressas em tipos pequenos. Não havia manchetes ou títulos; muitas vezes, as notícias eram separadas apenas por travessões. Em alguns casos, os textos eram introduzidos

2. COUTINHO, 1997, v. 6, p. 117-43. 
por rubricas genéricas como "Suicídio", "Envenenamento", "Antônio Conselheiro", "Obras do porto" etc. As notícias de outras praças, nacionais ou estrangeiras, eram publicadas na seção "Telegramas". A Gazeta divulgava também editais, anúncios classificados e publicidade, notadamente de remédios.

No final do século XIX, a Gazeta destacou-se como o jornal que mais espaço dava à literatura. No seu rodapé, abrigavam-se autores nacionais e estrangeiros, que publicavam romances-folhetins, crônicas e contos. Nas suas colunas, muitos poemas famosos de nossa literatura foram lidos pela primeira vez pelo grande público. Além disso, muitos autores hoje canônicos publicaram crônicas na folha de Ferreira de Araújo.

Reconhecido como jornalista e poeta, pela publicação de Poesias e por sua colaboração na Cidade do Rio e n'A Rua, Bilac foi convidado por Ferreira de Araújo a ser colaborador eventual da Gazeta de Notícias. ${ }^{3}$ Assim, no centro da primeira página da edição de 24 de abril de 1890 foi publicada a primeira crônica das centenas que depois seriam assinadas pelas iniciais O. B.: "Fortes...". Nesse texto inaugural, Bilac tratou de um espetáculo circense em que se destacava a perícia de um domador de elefantes.

Nesse mesmo ano, Bilac partiu para a Europa como correspondente da Cidade do Rio. Essa viagem pode ter retardado o estreitamento dos laços do poeta com a Gazeta, que iriam traduzir-se numa relação profissional estável somente em 22 de agosto de 1893, quando Bilac, convidado por Ferreira de Araújo a ser colaborador fixo da casa, inaugurou a coluna "Crônica livre". Por divergências políticas, o poeta deixara a Cidade do Rio, onde o talento de Patrocínio e seus companheiros seria colocado a serviço dos projetos golpistas do almirante Custódio José de Melo, ex-ministro da Marinha, que rompera com o presidente Floriano Peixoto. Compreende-se, então, porque o cronista classificou de "livre" sua nova coluna.

A consagração jornalística ocorreria no dia 7 de março de 1897, quando Ferreira de Araújo atribuiu ao poeta a incumbência altamente honrosa de substituir Machado de Assis (1839-1908), então considerado o maior escritor

3. Quando da morte do jornalista em 1900, Bilac enalteceu na sua crônica dominical o apoio que Ferreira de Araújo dispensava aos jovens. "Quando um poeta, um prosador, um jornalista, um pintor, um compositor começavam a romper às cotoveladas a massa espessa do anonimato, era ele um dos primeiros a desbravar-lhes o caminho, a pô-los ao sol, a empurrá-los para a evidência, a celebrar-lhes o valor ..." BILAC, 26 ago. 1900, p. 1, 3. col. 
brasileiro, na crônica semanal, a coluna de maior prestígio do periódico. Bilac, que considerava o cronista da coluna "A Semana" o seu mestre, lamentou, logo em uma de suas primeiras crônicas dominicais, que Machado, por estar adoentado, não pudesse narrar o trágico fracasso da segunda expedição contra Canudos, comandada pelo coronel Moreira César. O poeta das Panóplias não se sentia à altura dos acontecimentos: “... o mestre descansa, doente. E quem vem substituí-lo sai das baixas e fúteis regiões do Rodapé, em que é permitido ser prolixo e inconseqüente, leviano e paradoxal".

O rodapé, que abrigava romances-folhetins, contos e crônicas descontraídas, caracterizava-se por uma certa informalidade, o que se opunha ao caráter tradicional da crônica dominical, que, malgrado o estilo irônico de Machado de Assis, tratava dos assuntos sérios da semana anterior com a preocupação de informar e comentar. A crônica moderna, de um Fernando Sabino, de um Rubem Braga, origina-se justamente do rodapé ou folhetim, artigo sobre as questões do dia, que, segundo Antonio Candido, foi gradualmente encolhendo de tamanho e adquirindo certa gratuidade.

Herdando o modelo estabelecido por Machado, a crônica dominical de Olavo Bilac representava o comentário quase obrigatório dos principais fatos ocorridos na semana anterior, escolhidos de acordo com sua relevância ou com a repercussão alcançada. De modo geral, o texto era extenso e colocado na primeira página. O cronista assumia o papel de historiador, que nem sempre se desvencilhava de suas obrigações sem algum sacrifício.

Para fazer uma idéia justa da facilidade com que se esquecem, nas grandes cidades, os mais recentes acontecimentos, - é preciso ter esta obrigação de, ao cabo de todas as semanas, exumar os dias mortos, galvanizá-los, ressuscitá-los, pô-los de pé como Lázaros redivivos, e aprumálos em revista de mostra, diante do público.

Folheiam-se as coleções dos jornais, pesam-se os fatos, contemplamse a frio os escândalos, e com a mesma indiferença se examina tudo quanto despertou o riso e tudo quanto despertou a piedade. E que difícil arrancar dessa massa confusa de banalidades uma página, uma coluna, uma simples nota! O que consola é que, assim como se esquecem as cousas da semana, também se esquecem as crônicas.

4. BILAC, 14 mar. 1897 , p. 1, 2. col.

5. Cf. CANDIDO, 1992, p. 15. 
O cronista que, ao fim de dez anos de prática do ofício, se dispusesse a reunir e reler toda a sua obra, morreria de tédio e de horror, vendo-se pai de tão feia e desgraçada tribo de sensaborias. Ai! vida errada! e lembrar-se a gente de que toda a existência é isso mesmo, - e de que, na hora da morte, cada homem deve reconhecer que nada ganhou em ter vivido tanto, - como, na hora do exame de consciência, cada cronista reconheceria que nada lucrou com tanto haver escrito!

Se nessa crônica Bilac alardeia certa insatisfação com o trabalho de cronista, que lhe parece inútil por estar fadado ao esquecimento, exalta, em outra, a sua função ao compará-la com a dos jornalistas que apenas noticiam os fatos.

Os noticiaristas registram; os cronistas comentam. O noticiarista retira da mina a ganga de quartzo, em que o ouro dorme, sem brilho e sem préstimo; o cronista separa o metal precioso da matéria bruta que o abriga, e faz esplender ao sol a pepita rutilante.

Como se pode imaginar, o material reunido por esse trabalho de garimpo seria naturalmente heterogêneo. Por isso, a crônica dominical caracterizava-se pelos comentários de fatos os mais diversos, reunidos em um único texto apenas por acontecerem numa mesma semana. Era, de fato, uma manta de retalhos que se cosia aos sábados. ${ }^{8}$ Machado, mestre na arte da transição, saía-se muito bem da dificuldade, que Bilac enfrentava toda semana, de esvoaçar de assunto a assunto. Note-se como Bilac certa vez registrou a necessidade de realizar uma transição brusca: "Passar da morte para eleições não é fácil. Mas nós, cronistas, já estamos habituados às dificuldades da acrobacia. Não há pescoço de cronista que se torça num desses maravilhosos saltos".

Em outra crônica, Bilac compara o seu trabalho com o dos caixeiros viajantes, que carregam às costas, dentro dos seus baús, os produtos mais diversos. $\mathrm{Na}$ qualidade de "caixa" de assuntos, a crônica mistura "coisas desencontradas e opostas" assim como a vida.

6. BILAC, 4 dez. 1898, p. 1, 2. col.

7. BILAC, 21 jun. 1903, p. 1, 7. col.

8. Cf. BILAC, 19 jul. 1903, p. 1, 8. col.

9. BILAC, 29 jan. 1899, p. 1, 2. col. 
É impossível deixar de misturar, esta resenha da semana, o profano com o sagrado. Os cronistas são como os bufarinheiros, que levam dentro de suas caixas, rosários e alfinetes, fazendas e botões, sabonetes e sapatos, louças e agulhas, imagens de santos e baralhos de cartas, remédios para a alma e remédios para os calos, breves e pomadas, elixires e dedais. De tudo há de contar um pouco, esta caixa da Crônica: sortimento para gente séria e sortimento para gente fútil, um pouco de política para quem só lê os resumos dos debates do Congresso, e um pouco de carnaval para quem só acha prazer na leitura das seções carnavalescas.

Aqui está a caixa do bufarinheiro, leitor amigo: mete dentro dela a tua mão e serve-te à vontade. Não fui eu quem a encheu de tantas coisas desencontradas e opostas. Eu sou apenas o retalhista, o varejista dos assuntos. Quem me enche a caixa é a Vida, a fornecedora dos cronistas, - a Vida que nunca foi coerente nem metódica, - a Vida que tem sempre um milhão de contradições em um só minuto do seu curso acidentado e contraditório. ${ }^{10}$

De certa maneira, a crônica dos domingos pertencia mais ao jornal do que ao cronista, daí talvez a percepção deste trabalho como uma obrigação incontornável e tediosa. Fosse Machado ou Bilac, para a Gazeta de Notícias o importante era que algum escritor de prestígio enfeixasse num comentário bem escrito e agradável os principais acontecimentos noticiados durante a semana. Se, por um lado, faltava unidade à crônica semanal, ela assegurava, por outro lado, a unidade do jornal no intervalo de sete dias. Por isso, passaram os cronistas, mas a coluna da crônica dominical permaneceu incólume. Quando Bilac abandonou a função, encarregou-se dela João Rio, que publicaria a coluna "Cinematógrafo" sob o pseudônimo de Joe.

\section{A coluna de Bilac n'A Notícia}

A Notícia surgiu em 1894 como o primeiro vespertino a publicar matéria totalmente original, saindo da dependência das folhas da manhã. Com suas notícias frescas, procurava atender àqueles leitores exigentes que não suportavam esperar pelo jornal do dia seguinte para ficarem bem informados. A folha da tarde fazia da moderação a sua principal característica, evitando envolver-se em polêmicas. Traduzindo simbolicamente sua linha editorial, $A$

10. BILAC, 7 fev. 1904 , p. 1, 8. col. 
Notícia passou, a partir do segundo ano, a ser impressa em fino papel cor-derosa. A diagramação do vespertino era peculiar, pois o texto distribuía-se por seis colunas em que se utilizavam tipos graúdos.

Bilac manteve uma colaboração regular no período de 1894 a 1898 e sustentou uma coluna diária de 1899 a 1908. Para o vespertino, o poeta criou diversas seções de crônicas.

A coluna "Fantasia", assinada pelas iniciais O. B., foi publicada três vezes por semana, em dias variados, de 7 de agosto de 1895 a 18 de fevereiro de 1897. Nela, o poeta expressava uma visão muito subjetiva da paisagem urbana do Rio de Janeiro.

De 9 de junho de 1897 a 27 de julho de 1898, Bilac enfeixou seus textos, assinados geralmente com o pseudônimo Flaminio e publicados no rodapé da segunda página, sob a epígrafe "Crônica". Tratava-se da reunião de notas diversas sobre acontecimentos da semana, mas a seleção dos assuntos era estritamente pessoal, ou seja, o cronista não se sentia obrigado a tratar dos fatos de maior repercussão.

Durante um ano e um dia, de 5 de junho de 1899 a 5 de junho de 1900, o poeta tornou-se um pertinaz consulente de velhos alfarrábios, ${ }^{11}$ de onde retirava matéria-prima para escrever a sua seção diária "A data", publicada na primeira coluna da segunda página e assinada com a inicial B. A tarefa do cronista era rememorar fatos históricos ocorridos na data de cada edição. Mas muitas vezes essa visita ao passado servia de pretexto para tratar dos problemas do presente. A fórmula agradou ao público leitor.

No dia 6 de agosto de 1900, teve início uma coluna diária, assinada com a inicial B., que seria mantida regularmente na primeira coluna da segunda página até 12 de novembro de 1908. As freqüentes viagens do poeta a S. Paulo, estâncias hidrominerais de Minas Gerais, Buenos Aires e cidades da Europa não interromperam o cotidiano "Registro"; já a crônica dominical da Gazeta de Notícias foi nessas ocasiões assumida por outros autores.

O "Registro" era uma espécie de diário pessoal em que se expressavam emoções vividas, fatos testemunhados, recordações, leituras realizadas etc. De acordo com a metáfora proposta no primeiro texto da série,

11. Cf. B., 27 jun. 1899, p. 2, 1. col.

12. Ao menos, era o que garantia o jornal. "Raras seções d'A Notícia têm tido o sucesso da Data, que ontem terminou." 6 jun. 1900, p. 1, 2. col. 
a coluna seria como os apontamentos de um viajante que observa a paisagem por uma janela de vagão de trem.

Registro, como rezam os dicionários, é um nome transitivo; faz-se o registro de alguma coisa. O título da coluna manifesta, portanto, uma certa indeterminação temática, que permitiu ao poeta tratar dos mais variados assuntos e incorporar à sua crônica os mais diversos gêneros: a narrativa, a dissertação, o diálogo dramático etc. No entanto, a coluna d'A Notícia permitiu a Bilac manter a unidade temática em cada texto, o que só era possível na Gazeta de Notícias por meio de algum expediente retórico.

A coluna representava um projeto pessoal, pois fora concebida por Bilac, que a manteve por mais de oito anos, a despeito de viagens e doenças. Na véspera de viajar para a Europa em 1904, o poeta comprometeuse com seus leitores a enviar de onde estivesse a sua crônica diária: "Este Registro foi sempre o meu 'diário', todos os dias aberto, todos os dias escrito, fixando as impressões dos meus olhos, do meu espírito, da minha inquieta curiosidade. Não haveria motivo para que o 'diário' fosse interrompido agora". ${ }^{13}$

Com efeito, nota-se na coluna d'A Notícia um caráter mais subjetivo, impressionista, muitas vezes descontraído - em suma, um lirismo difuso. O cronista expressava seu ponto de vista estritamente pessoal; por isso, às vezes há nos textos a presença de verbos na primeira pessoa do singular. Ao enviar crônica da capital francesa, por exemplo, Bilac fez questão de tratar de suas experiências e impressões pessoais.

Saí do Hotel d'Orsay, atravessei o Sena e o Jardim das Tulherias, fartei os olhos na contemplação encantada da praça da Concórdia e dos Campos Elísios, segui até a Madeleine, e entrei nos grandes boulevards, - como um glóbulo de sangue perdido na circulação dessa larga artéria de Paris. ${ }^{14}$

Como conseqüência da informalidade adotada, algumas crônicas incorporam até mesmo o leitor como interlocutor explícito. Leia-se, por exemplo, o penúltimo parágrafo da crônica de despedida já citada acima.

Não nos há de a viagem separar, amigo leitor. Tu irás comigo, como meu confidente e camarada, pelos mares e pelas terras, vendo e ouvindo o

13. B., 9 abr. 1904 , p. 2, 1. col.

14. B., 13 jun. 1904 , p. 2, 1. col. 
que eu vir e ouvir por esse mundo em fora. Farei o possível para te não aborrecer; e, armado de tolerância e pachorra, tu continuarás a ouvir as minhas confidências, concordando ou não comigo, mas sempre reconhecendo (assim o espero) que te falo com o coração perto da boca, sem mentira e sem hipocrisia. ${ }^{15}$

Com esse recurso retórico, Bilac faz com que seus textos adquiram muitas vezes o tom de conversa amena e despreocupada entre camaradas. Um atributo comum contribuía para aproximar intimamente leitor e cronista: a identidade carioca. Ao contrário da Gazeta, de cuja tiragem uma parte significativa seguia para os estados, $A$ Notícia circulava principalmente na cidade do Rio de Janeiro, o que quase impunha uma preocupação primordial com os problemas da cidade. Em crônica a respeito do aniversário da cidade, Bilac definiu o "Registro" como "uma casa carioca como poucas, carioca da gema, carioca desde os alicerces até as telhas"."16

No momento em que se inicia a coluna, o grande problema da cidade na opinião de Bilac, dos médicos e de parte da imprensa e do governo era a insalubridade. Ruas sujas e esburacadas, saneamento básico inexistente ou insuficiente, doenças endêmicas e aglomeração de pessoas em cortiços eram alguns dos problemas que o poeta atacava em suas crônicas.

O cronista do "Registro" foi um dos grandes defensores da Regeneração do Rio de Janeiro promovida pelo prefeito Pereira Passos com total apoio do presidente Rodrigues Alves. Na coluna, encontram-se desde projetos de reforma urbanística até o apoio explícito às medidas muitas vezes discricionárias da prefeitura.

A passagem por outras cidades levou o cronista a compará-las com a sua cidade natal. Para Bilac, a cidade de Buenos Aires, saneada, arborizada e dotada de largas avenidas perfeitamente calçadas, era a prova viva de que seria possível reformar o Rio de Janeiro. ${ }^{17}$ O exemplo de São Paulo era freqüentemente lançado à face das autoridades cariocas, ${ }^{18}$ que, segundo o cronista, deveriam envergonhar-se da rapidez com que os paulistanos faziam da sua cidade um

15. B., 9 abr. 1904 , p. 2, 1. col.

16. B., 20 jan. 1905 , p. 2, 3. col.

17. B., 21 ag. 1900 , p. 2, 1. col. B., 3 set. 1900, p. 2, 1. col.

18. B., 3 jan. 1902 , p. 2, 1. col. 
modelo de salubridade e organização. ${ }^{19}$ Até mesmo a pequena Campinas humilhava a Capital Federal, ${ }^{20}$ pois pusera fim à febre amarela com simples mas eficientes medidas de saneamento.

Porém, de todas as cidades conhecidas por Bilac, nenhuma superava Paris, que o poeta visitou pela segunda vez em 1904 e de onde remetia as suas crônicas, em que expressou seu encantamento com as belezas da cidade, ${ }^{22}$ com a intensidade da sua vida intelectual, ${ }^{23}$ com o grande teatro da Comédie Française ${ }^{24}$ e com a difusão da alfabetização.

Do ponto de vista formal, o "Registro", por sua brevidade, seu "ar de coisa sem necessidade", seu tom ligeiro e seu aspecto de conversa despretensiosa e bem-humorada, coloca Bilac como precursor da crônica contemporânea. ${ }^{26}$ Entretanto, a simplicidade e a graça do texto não eram, do ponto de vista ideológico, gratuitas, pois permitiam ao cronista insinuar-se no espírito do leitor a fim de convencê-lo das idéias que defendia, principalmente a de que o Rio de Janeiro necessitava de mudanças radicais para resolver definitivamente suas velhas mazelas: a sujeira e as doenças tropicais.

19. B., 19 fev. 1902, p. 2, 1. col.

20. B., 18 mar. 1902 , p. 2, 1. col.

21. B., 19 fev. 1902, p. 2, 1. col.

22. B., 13 jun. 1904 , p. 2, 1. col.

23. B., 6 jul. 1904 , p. 2, 1. col.

24. B., 30 set. 1904 , p. 2, 1. col.

25. B., 15 jun. 1904 , p. 2, 1. col.

26. CANDIDO, 1992, p. 15. 
Disponível em: bttp://www.letras.ufmg.br/poslit

Abstract: Olavo Bilac (1865-1918) was responsible for an important innovation of Brazilian chronicle by means of his "Registro", a section of daily chronicles published from 1900 to 1908 by A Notícia, an evening paper of Rio de Janeiro. Until then, the chroniclers accomplished a predetermined function: to comment on main events of the passed week. In this way, their fragmentary texts had no unity. The other way about, the Parnassian poet conquered the liberty to deal with an only single subject from a totally personal and free point of view.

Key words: Brazilian literature; Chronicle; Olavo Bilac.

\section{Referências Bibliográficas}

B. [Olavo Bilac] A data. A Notícia. Rio de Janeiro, 27 jun. 1899. p. 2, 1. col.

B. Registro. A Notícia. Rio de Janeiro, 9 abr. 1904. p. 2, 1. col.

B. Registro. A Notícia. Rio de Janeiro, 13 jun. 1904. p. 2, 1. col.

B. Registro. A Notícia. Rio de Janeiro, 9 abr. 1904. p. 2, 1. col.

B. Registro. A Notícia. Rio de Janeiro, 20 jan. 1905. p. 2, 3. col.

B. Registro. A Notícia. Rio de Janeiro, 21 ag. 1900. p. 2, 1. col.

B. Registro. A Notícia. Rio de Janeiro, 3 set. 1900. p. 2, 1. col.

B. Registro. A Notícia. Rio de Janeiro, 3 jan. 1902. p. 2, 1. col.

B. Registro. A Notícia. Rio de Janeiro, 19 fev. 1902. p. 2, 1. col.

B. Registro. A Notícia. Rio de Janeiro, 18 mar. 1902. p. 2, 1. col.

B. Registro. A Notícia. Rio de Janeiro, 19 fev. 1902. p. 2, 1. col.

B. Registro. A Notícia. Rio de Janeiro, 13 jun. 1904. p. 2, 1. col.

B. Registro. A Notícia. Rio de Janeiro, 6 jul. 1904 . p. 2, 1. col.

B. Registro. A Notícia. Rio de Janeiro, 30 set. 1904. p. 2, 1. col.

B. Registro. A Notícia. Rio de Janeiro,15 jun. 1904. p. 2, 1. col.

BILAC, Olavo. Crônica. Gazeta de Notícias. Rio de Janeiro, 26 ag. 1900. p. 1, 3. col.

BILAC, Olavo. Crônica. Gazeta de Notícias. Rio de Janeiro, 14 mar. 1897. p. 1, 2. col.

BILAC, Olavo. Crônica. Gazeta de Notícias. Rio de Janeiro, 4 dez. 1898. p. 1, 2. col.

BILAC, Olavo. Crônica. Gazeta de Notícias. Rio de Janeiro, 21 jun. 1903. p. 1, 7. col.

BILAC, Olavo. Crônica. Gazeta de Notícias. Rio de Janeiro, 19 jul. 1903. p. 1, 8. col.

BILAC, Olavo. Crônica. Gazeta de Notícias. Rio de Janeiro, 29 jan. 1899. p. 1, 2. col.

BILAC, Olavo. Crônica. Gazeta de Notícias. Rio de Janeiro, 7 fev. 1904. p. 1, 8. col. 
Disponivel em: bttp://www.letras.ufmg.br/poslit

CANDIDO, Antonio. A vida ao rés-do-chão. In: SETOR de Filologia da Fundação Casa de Rui Barbosa. A crônica. O gênero, sua fixação e suas transformações no Brasil. Campinas: Ed. da Unicamp, Rio de Janeiro: FCRB, 1992. p. 13-22.

COUTINHO, Afrânio. Ensaio e crônica. In: COUTINHO, Afrânio (Dir.). COUTINHO, Eduardo de Faria (Co-dir.). A literatura no Brasil. 4. ed. São Paulo: Global, 1997. v. 6, p. 117-43. 